
\title{
25 Research Square \\ Flexible Material Formulations for 3D Printing of Porous Beds with Applications in Bioprocess Engineering
}

\section{Simone Dimartino ( $\sim$ Simone.Dimartino@ed.ac.uk)}

The University of Edinburgh https://orcid.org/0000-0002-9695-1278

\section{Giuseppe Rafael Galindo-Rodriguez}

The University of Edinburgh

Ursula Simon

The University of Edinburgh

\section{Mariachiara Conti}

The University of Edinburgh

\section{Sulaiman Sarwar}

The University of Edinburgh

\section{Selva Athi Narayanan}

The University of Edinburgh

\section{Qihao Jiang}

The University of Edinburgh

\section{Nick Christofi}

Recircle Ltd

\section{Research Article}

Keywords: Biomaterials, Additive manufacturing, Chromatography, Immobilized enzyme bioreactor, Bacterial Biofilm Bioreactor

Posted Date: January 11th, 2022

DOI: https://doi.org/10.21203/rs.3.rs-1166391/v1

License: (c) (i) This work is licensed under a Creative Commons Attribution 4.0 International License. Read Full License 


\section{Abstract}

Background: 3D printing is revolutionizing many industrial sectors and has the potential to enhance also the biotechnology and bioprocessing fields. Here, we propose a new flexible material formulation to 3D print support matrices with complex, perfectly ordered morphology and with tuneable properties to suit a range of applications in bioprocess engineering.

Findings: Supports for packed-bed operations were fabricated using functional monomers as the key ingredients, enabling matrices with bespoke chemistry such as charged groups, chemical moieties for further functionalization, and hydrophobic/hydrophilic groups. Other ingredients, e.g. crosslinkers and porogens, provide the opportunity to further tune the mechanical properties of the supports and the morphology of their porous network. Through this approach, we fabricated and demonstrated the operation of Schoen gyroid columns with I) positive and negative charges for ion-exchange chromatography, II) enzyme bioreactors with immobilized trypsin to catalyse hydrolysis, and III) bacterial biofilms bioreactors for fuel desulfurization.

Conclusions: This study demonstrates a simple, cost-effective and flexible fabrication of customized 3D printed supports for different biotechnology and bioengineering applications.

\section{Introduction}

In the last decade we have witnessed the booming of additive manufacturing (AM, also 3D printing), including its related fabrication technologies, materials, and applications. The biotechnology and bioprocessing fields have been significantly influenced by AM, with reports spanning upstream and downstream processing, including sorting and selection of cell strains (Lin et al., 2016), bioreactors (Saha et al., 2018), harvesting (Shakeel Syed et al., 2017), filtration (Tan \& Franzreb, 2020), chromatography (Salmean \& Dimartino, 2019), and extraction (H. Wang et al., 2017). One of the most popular AM methods employed in bioengineering is digital light processing (DLP) where a three-dimensional model is built, layer upon layer, by selectively curing a photo-sensible liquid resin. Reasons for the success of DLP in biotechnology include its relatively low cost, fast speed (litre sized objects can be printed overnight), and high resolution (generally in the order of $50 \mu \mathrm{m}$ ).

Historically, AM was primarily in the domain of the automotive, aerospace, and biomedical industries which favoured materials with mechanical properties over chemical characteristics and fabricated nonporous structures where strength and stiffness are key. On the other hand, bioprocess applications often require porous materials to maximize the total surface area available for cell adhesion, adsorption, and allow intraparticle mass transfer. Besides, materials in the biotechnology industry heavily exploit chemical characteristics such as electrostatic charge and hydrophobic behaviour to appropriately modulate their interactions with species as diverse as cells, proteins, and small metabolites. This requirement contrasts the status quo where the composition of commercially available AM materials is IP protected, making it impossible to rationally design material-species interactions of interest. Proprietary 
compositions also complicate compliance with FDA or EMEA requirements, hindering adoption of 3D printing in the biomanufacturing industry.

Here, we present a novel polymeric formulation for DLP 3D printing which can be easily tuned to adjust its chemical, porous, and mechanical properties of printed parts. The formulation consists of a few simple ingredients, including monomers and crosslinkers to create the polymeric network (Figure 1a), a UV photoinitiator to trigger the photopolymerization reaction, a photoabsorber to increase the resolution of the printed model, and porogenic components. The key feature of the proposed formulation lays in the use of bifunctional monomers bearing both a (meth)acrylate functionality for photopolymerization and a suitable chemical moiety for biomolecular interactions, e.g. charged groups, alkyl or aryl groups, or reactive groups for successive covalent immobilization of a desired ligand. By appropriate selection of the bifunctional monomers, different materials with different surface derivatizations to suit a range of applications in bioprocess engineering can be obtained. Furthermore, the nature and relative concentration of the components making up the overall formulation will directly impact on the propagation kinetics of the free-radical polymerization reaction, in turn affecting the morphology of the resulting polymeric network and its porous microstructure (e.g. surface area, average pore size, pore size distribution) (Barner-Kowollik et al., 2014; Buback, 2009). In this work, we manipulated these characteristics to produce different formulations for DLP printing, and obtain porous monoliths with different chemical and macroporous properties for use in chromatography, immobilized enzyme bioreactors, and biofilm bioreactors.

\section{Materials And Methods}

\subsection{Composition of material formulations}

All chemicals employed are listed in the SI. All fomulations included $48 \% \mathrm{v} / \mathrm{v}$ cyclohexanol and $12 \% \mathrm{v} / \mathrm{v}$ dodecanol as porogens, and $1 \% \mathrm{w} / \mathrm{v}$ omirad 819 as photoinitiator. A mixture of poly(ethylene glycol) diacrylate (PEGDA, 12\% v/v) and alkoxylated pentaerythrioltetraacrylate (SR494, 12\% v/v) as crosslinkers, and $0.125 \% \mathrm{w} / \mathrm{v}$ Tinuvin 326 as photoabsorber was employed for the acrylate (AETAC and CEA) formulations. The relative concentration of AETAC and CEA was varied to adjust the ligand denisity $(0,4$, $8,12,16 \% \mathrm{vol})$, with di(ethylene glycol) ethyl ether acrylate (DEGEEA) as non-functional monomer to obtain a total monomer concentration of $16 \%$ vol. The methacrylate formulation was composed of MAETAC (12\% v/v) and HEMA (12\% v/v) functional monomers, ethylene glycol dimethacrylate (EDMA, $16 \% \mathrm{v} / \mathrm{v})$ crosslinker and Tinuvin $326(0.1 \% \mathrm{w} / \mathrm{v})$ photoabsorber.

\subsection{Model Design, Fabrication, and Characterization}

Computer-Aided Design (CAD) models of hollow cylinders and gyroidal columns were created on Fusion 360 (Autodesk, USA), exported as STL files and sliced using Netfabb 2017 (Autodesk, USA). A Solflex 350 (W2P Engineering, Austria) DLP printer was employed to fabricate all parts. Post-printing, the parts were washed three times in IPA in an ultrasonic bath (Allendale Ultrasonics, UK) and then fully cured in water with a xenon Otoflash G171 unit (NK-Optik, Germany). The parts were stored in sterile 0.1 M phosphate 
buffer until use. A TM4000Plus SEM microscope (Hitachi, Japan) and a Zeiss Crossbeam 550 FIB SEM (Jena, Germany) were used for SEM imaging, with samples prepared by freeze-fracturing with liquid nitrogen, drying in ethanol, followed by a final wash in HMDS before sputter coating using an Emscope SC500 (Bio-Rad, UK). Mean pore sizes and distributions were evaluated from the SEM images.

\subsection{Chromatography}

3D printed hollow cylinders were employed in batch experiments by inserting the cylinders into 96 -well plates and reading the absorbance using a Modulus II microplate reader (Turner BioSystems, USA). Batch adsorption on the AEX material (based on the AETAC monomer) involved an initial equilibration in phosphate buffer $(20 \mathrm{mM}, \mathrm{pH} 7.4)$ for a minimum of $48 \mathrm{~h}$, followed by addition of a BSA solution (0-32 $\mathrm{mg} / \mathrm{mL}$ ) in phosphate buffer. Similarly, CEX materials (based on the CEA monomer) were equilibrated in binding buffer (20 mM phosphate, $\mathrm{pH} 7.4$ ) before loading a LYS solution $(0-4 \mathrm{mg} / \mathrm{mL})$. Flow experiments were carried out at $1 \mathrm{~mL} / \mathrm{min}$ using gyroidal columns (50\% external porosity, $500 \mu \mathrm{m}$ wall thickness) slotted into $10 \mathrm{~mm}$ i.d. SNAP® glass housing (Essential Life Solutions, USA) and connected to an ÄKTA ${ }^{\text {TM }}$ Purifier 10 system (GE Healthcare, USA) equipped with a UV detector to record absorbance at $280 \mathrm{~nm}$.

\subsection{Immobilized Enzyme Bioreactor}

Trypsin was immobilized on CEA supports via the EDC protocol. Briefly, the 3D printed materials were equilibrated in a $0.1 \mathrm{M}$ sodium phosphate $(\mathrm{pH} 7.4)$ activation buffer, followed by a 35-min immersion on activation buffer containing 1:10 molar excess of EDC with respect to carboxylic groups. After extensive washing in activation buffer, coupling of the enzyme was obtained by soaking the 3D printed models in trypsin solutions $(1-10 \mathrm{mg} / \mathrm{mL})$ in $0.1 \mathrm{M}$ phosphate buffer $\mathrm{pH} 7.4$ for 2 hours at room temperature. Nonbound trypsin was removed by washing with $0.1 \mathrm{mM}$ Tris buffer $(\mathrm{pH} 8)$. The amount of trypsin immobilized on the 3D printed materials was calculated as the difference of the initial and final concentration of trypsin using the BCA assay (Smith et al., 1985). A control experiment was run by adding trypsin solutions to non-activated cylinders. Similar to the chromatography runs, the activity of the immobilized trypsin was tested both in batch (hollow cylinders in multi-well plate format) and dynamic conditions (gyroids with $50 \%$ external porosity, $500 \mu \mathrm{m}$ wall thickness, $25 \mathrm{~mm}$ diameter, $10 \mathrm{~mm}$ bed height, flow rate ranging $0.5-8 \mathrm{~mL} / \mathrm{min}$ ). In both cases, after equilibration in $50 \mathrm{mM}$ Tris buffer $\mathrm{pH}$ 8, a 1 mM BAEE substrate solution in $50 \mathrm{mM}$ Tris buffer $\mathrm{pH} 8$ was fed to the 3D printed models, and formation of the hydrolysis product (BA) product was monitored at $253 \mathrm{~nm}$.

\subsection{Bacterial Biofilm Bioreactor}

Biofilms of Rhodococcus opacus IEGM 248 cells were obtained by perfusing fresh cultures (exponential growth phase) for 3 days in recirculation mode $(1 \mathrm{~mL} / \mathrm{min}$ ) through gyroidal supports (50\% external porosity, $2 \mathrm{~mm}$ wall thickness, $10 \mathrm{~mm}$ diameter, $40 \mathrm{~mm}$ height) in a glass column, followed by column washes with quarter strength Ringer's solution to remove non-adsorbed biomass (free cells). The obtained biofilms were then grown by continuous feed $(2 \mathrm{~mL} / \mathrm{min})$ of a mineral salts medium (MSM, 2.0 $\mathrm{g} / \mathrm{l}$ sucrose, $7 \mathrm{~g} / \mathrm{l} \mathrm{Na}{ }_{2} \mathrm{HPO}_{4}, 6 \mathrm{~g} / \mathrm{I} \mathrm{KH}_{2} \mathrm{PO}_{4}, 2 \mathrm{~g} / \mathrm{l} \mathrm{NH} \mathrm{Cl}_{4} 0.2 \mathrm{~g} / \mathrm{l} \mathrm{MgCl} \cdot 6 \mathrm{H}_{2} \mathrm{O}, 0.03 \mathrm{~g} / \mathrm{l} \mathrm{CaCl} 2 \cdot 2 \mathrm{H}_{2} \mathrm{O}, 0.001 \mathrm{~g} / \mathrm{l}$ $\mathrm{FeCl}_{3} \cdot 6 \mathrm{H}_{2} \mathrm{O}$ ) spiked with $0.2 \mathrm{mM} \mathrm{BT}$ as sole sulphur source. According to the biodesulfurization reaction, 
BT is converted into phenolic compounds (principally hydroxyphenylacetaldehyde) whose presence in the perfusate was confirmed using the Gibbs test (Gibbs, 1927; W. Wang et al., 2013).

\section{Results And Discussion}

\subsection{Structure morphology at the macro and micro scales}

A Schoen gyroid was selected for fabricating the structured monoliths (Figure 1b,d,f). Gyroids are members of Triply Periodic Minimal Surfaces (TPMS), highly versatile geometries with maximized surface area for mass transfer (Femmer et al., 2015) and excellent load-bearing stiffness. TPMS are described by simple equations and their properties in terms of size, surface area, hydraulic diameter, bed porosity, tortuosity, wall thickness, etc. can be tuned by altering the equation parameters (Schoen, 2012). We first simulated fluid flow and solute dispersion to validate the suitability of the gyroid topology for packed beds. The gyroid structure showed 5 fold higher efficiency (measured in terms of minimum reduced plate height, Figure $1 \mathrm{~b})$ and 4 fold higher permeability $\left(6.4 \times 10^{-14} \mathrm{~m}^{2}\right)$ compared to traditional random packing of spherical particles $\left(1.61 \times 10^{-14} \mathrm{~m}^{2}\right)$ (Schure et al., 2004). In particular, the interconnected gyroid lattice ensured appropriate radial intermixing, in turn reducing axial dispersion and band broadening, while showing minimal flow resistance with lower pressure drops than random beds.

Use of porogens enabled formation of a highly interconnected porous network defined by polymeric globules (Figure S1). The final porous microstructure was principally determined by polymer chemistry, with acrylate-based formulations producing smaller pores $(271 \pm 120 \mathrm{~nm}$ for the AETAC and $289 \pm 112$ $\mathrm{nm}$ for the CEA materials, Figure S1d) than methacrylate-based formulations (905 $\pm 410 \mathrm{~nm}$ for the MAETAC material). This is consistent with the higher reactivity of acrylates over methacrylate groups (Barner-Kowollik et al., 2014), with acrylates generating a higher number of polymerization nuclei, in turn leading to smaller globules and smaller pores than methacrylates. Fine tuning of the porous characteristics of the 3D printed matrices can be achieved by adjusting the overall composition as its nature and concentration directly affects the kinetic and thermodynamic properties of the mixture. This ultimately enables modulation of diffusional mass transfer within the 3D printed scaffold and the surface area available for adsorption and reaction.

\subsection{Application as stationary phase for ion exchange chromatography}

We first demonstrate use of the proposed formulation for chromatography applications. In particular, strong anion and weak cation exchange monoliths were fabricated using resins with bifunctional acrylates bearing positive quaternary amine (AETAC monomer) and negative carboxyl groups (CEA monomer) respectively (Figure 1a). lon-exchangers with varying ligand densities were obtained by altering the concentration of the functional monomers in the formulation, enabling adjustment and optimization of the adsorption characteristics towards the target solute. The ion exchangers were initially 3D printed as hollow cylinders (Figure 1c-e), and adsorption of pure Bovine Serum Albumin (BSA) and 
lysozyme (LYS) was measured in batch conditions on the AETAC and CEA materials, respectively. Maximum binding capacities of $104.2 \pm 10.6 \mathrm{mg}$ of BSA per $\mathrm{mL}$ of AETAC-based support, and $108.1 \pm$ $25.9 \mathrm{mg}$ of LYS per $\mathrm{mL}$ of CEA-based material were recorded (Figure $2 \mathrm{a}$ and $2 \mathrm{~b}$ ), about 5 fold higher than for commercial monoliths (Hahn et al., 2002) and chromatographic membranes (Boi et al., 2020) and in line or above standard chromatographic resins (Staby et al., 2005). Testing in dynamic conditions was carried out using Schoen gyroid columns (Figure 1f-h) by loading BSA and myoglobin (MYO) onto the AETAC material (Figure 2c, Simon et al., 2020) and BSA and LYS on the CEA material (Figure 2d). The chromatograms reveal elution patterns in line with the electrostatic interactions established at the buffer's $\mathrm{pH}$, thus confirming the availability of the surface quaternary amine and carboxyl groups to establish appropriate electrostatic interactions with the protein models. Also, approximately $90 \%$ of the proteins adsorbed were recovered during elution for both materials, demonstrating that the strength of the electrostatic interactions can be appropriately tuned to enable bind and elute operation of the ionexchangers.

\subsection{Application as immobilised enzyme bioreactor}

The potential to fabricate immobilized enzyme bioreactors for biotransformations was tested by covalently immobilizing trypsin onto the free carboxylic groups of the CEA material. In particular, 3D printed supports were exposed to trypsin solutions having different enzyme concentrations, leading to materials with progressively increasing immobilized trypsin, up to a maximum density of $7.5 \pm 0.04 \mathrm{mg}$ of trypsin per g of support, corresponding to $66 \%$ utilization of the theoretical carboxyl groups. Enzymatic activity was tested in batch experiments by introducing $\mathrm{N}$-a-benzoyl-L-arginine ethyl ester hydrochloride (BAEE) to 3D printed hollow cylinders, and monitoring the formation of $\mathrm{N}$-a-benzoyl-D,L-arginine (BA) as the product of the enzyme catalyzed reaction. Results indicated that the immobilized trypsin retained its hydrolytic activity (Figure 3a). Dynamic experiments were carried out using 3D printed gyroids to demonstrate the operation of the bioreactor in steady-state, continuous mode. Five flow rates in the range of $0.5-8 \mathrm{~mL} / \mathrm{min}$ were tested and product formation was verified for all of them. As the flow rate increased, the concentration of product in the effluent stream decreased due to a combination of mass transport phenomena and actual reaction kinetics (Figure 3b). Yet, productivity, expressed in terms of product formed per unit time, showed a proportional growth with increased flow rates due to higher throughputs. This is consistent with other case studies for continuous packed bed reactors bearing immobilized enzymes (Halim et al., 2009).

\subsection{Application as bacterial biofilm bioreactor}

The bioreactor concept was extended to whole-cell biocatalysis. We selected the biodesulfurization reaction catalyzed by immobilized Rhodococcus opacus as a case study for an emerging eco-friendly alternative to traditional desulfurization techniques employed in oil refineries (Mohebali \& Ball, 2016). $R$. opacus has negatively charged cell membrane rich in mycolic acid. Accordingly, the support material was engineered with positively charged and hydrophilic bifunctional monomers displaying quaternary amine (MAETAC) and hydroxyl groups (HEMA, Figure 1a) to enhance cell immobilization. A methacrylate functionality was chosen to enable autoclaving of the supports for repeated use. Immobilization 
experiments with standard culture medium revealed that $R$. opacus bacteria formed stable and healthy biofilms on the 3D printed supports (Figure 4a). In particular, a biofilm covering the external surface of the supports was obtained, with rod-like morphology typical of filamentous aggregates of mature Rhodococcus cells (approximately 4.0 and 0.5 microns in length and width, respectively). Since the pore size of the matrix is between 0.4 and 1.0 microns, the biofilm could penetrate into the porous architecture, aiding cell adhesion and biofilm stability. The gyroid-based bioreactor was tested for the biodesulfurization of benzothiophene (BT) in perfusion mode. Results reveal conversion of BT into phenolic end products (Figure $4 \mathrm{~b}, \mathrm{c}$ ), proving the biodesulfurization potential of the 3D printed bacterial biofilm bioreactor. In addition, production of phenolic compounds increases over time, indicating adaptation of the biofilm to the reacting conditions and confirming the biocompatibility of the support material with a thriving bacterial population.

\section{Conclusions}

Taken together, the versatile material formulation here presented could be used to create complex threedimensional matrices for chromatography and bioreactors. The chemical, physical, mechanical and microporous properties of the supports can be easily tuned by changing the composition of the DLP resin formulation. For example, a combination of bifunctional monomers bearing alkyl chains and polar groups could be employed to tune the hydrophobic/hydrophilic as well as charged state of the matrices. We expect this versatility, coupled with cost-effective and rapid DLP 3D printing (all models were 3D printed in a few hours), will truly enable fabrication of complex three dimensional architectures to suit a range of diverse experimental requirements for a multitude of applications in bioprocess engineering.

\section{Abbreviations}

\section{AM}

Additive manufacturing

DLP

Digital light processing

TPMS

Triply periodic minimal surfaces

AETAC

[2-(acryloyloxy)ethyl] trimethylammonium chloride

MAETAC

[2-(methacryloyloxy)ethyl] trimethylammonium chloride

CEA

2-carboxyethyl acrylate

HEMA

Hydroxyethyl methacrylate

BSA 
Bovine serum albumin

LYS

Lysozyme

MYO

Myoglobin

BAEE

$\mathrm{N}$-a-benzoyl-L-arginine ethyl ester hydrochloride

BA

N-a-benzoyl-D,L-arginine

BT

Benzothiophene

HMDS

Hexamethyldisilazane.

\section{Declarations}

\section{Author's contributions}

QJ performed the simulations of the gyroidal scaffold. US, MC, GG, SS and SAN designed and conducted the experiments. US, MC, GG, SS and SAN analysed the experimental data. NC gave guidance to the design of the experiments. SD conceived the research. SD wrote the first draft of the manuscript. SD, QJ, US, MC, GG, SS and SAN contributed to the writing and editing of the manuscript. All authors read and approved the final version of the manuscript.

\section{Acknowledgements}

We are thankful to the Industrial Biotechnology Innovation Centre (IBiolC) for funding (grant numbers 2019-2-3 and FF-2020-13). M.C. acknowledges the department of Chemical Engineering of the University of Bologna for a study abroad scholarship; U.S. acknowledges UoE for funding her PhD scholarship; G.G.R. acknowledges Conacyt for funding his PhD scholarship; S.S. acknowledges UoE for funding his undergraduate research scholarship. We also acknowledge the use of the Cryo FIB/SEM bought with the EPSRC grant EP/P030564/1 and Thomas Glen for help with the image acquisition. We are also grateful to BASF, IGM resins and Arkema-Sartomer for providing us with free samples.

\section{Funding}

Industrial Biotechnology Innovation Centre (IBioIC), grant no. 2019-2-3 and FF-2020-13, provided funding for the Bacterial Biofilm Bioreactors experiments. 


\section{Availability of data and materials}

All data generated and analysed during this study are included in this published article and its supplementary information file.

\section{Ethics approval and consent to participate}

Not applicable

\section{Consent for publication}

Not applicable

\section{Competing interests}

The authors declare that they have no competing interests

\section{References}

1. Barner-Kowollik C, Beuermann S, Buback M, Castignolles P, Charleux B, Coote ML, Hutchinson RA, Junkers T, Lacík I, Russell GT, Stach M, Van Herk AM (2014) Critically evaluated rate coefficients in radical polymerization-7. Secondary-radical propagation rate coefficients for methyl acrylate in the bulk. Polym Chem 5(1). https://doi.org/10.1039/c3py00774j

2. Boi C, Malavasi A, Carbonell RG, Gilleskie G (2020) A direct comparison between membrane adsorber and packed column chromatography performance. J Chromatogr A 1612:460629. https://doi.org/10.1016/j.chroma.2019.460629

3. Buback M (2009) II. Fundamentals of free-radical polymerization propagation kinetics in radical polymerization studied via pulsed laser techniques. Macromolecular Symposia 275-276(1). https://doi.org/10.1002/masy.200950111

4. Femmer T, Kuehne AJC, Torres-Rendon J, Walther A, Wessling M (2015) Print your membrane: Rapid prototyping of complex 3D-PDMS membranes via a sacrificial resist. J Membr Sci 478:12-18. https://doi.org/10.1016/j.memsci.2014.12.040

5. Gibbs HD (1927) Phenol tests: III. The indophenol test. J Biol Chem 72(2):649-664

6. Hahn R, Panzer M, Hansen E, Mollerup J, Jungbauer A (2002) Mass transfer properties of monoliths. Sep Sci Technol 37(7):1545-1565. https://doi.org/10.1081/SS-120002736

7. Halim SFA, Kamaruddin AH, Fernando WJN (2009) Continuous biosynthesis of biodiesel from waste cooking palm oil in a packed bed reactor: Optimization using response surface methodology (RSM) and mass transfer studies. Bioresour Technol 100(2):710-716. https://doi.org/10.1016/j.biortech.2008.07.031 
8. Lin X, Yao J, Dong H, Cao X (2016) Effective Cell and Particle Sorting and Separation in ScreenPrinted Continuous-Flow Microfluidic Devices with 3D Sidewall Electrodes. Ind Eng Chem Res 55(51):13085-13093. https://doi.org/10.1021/acs.iecr.6b03249

9. Mohebali G, Ball AS (2016) Biodesulfurization of diesel fuels - Past, present and future perspectives. Int Biodeterior Biodegradation 110:163-180. https://doi.org/10.1016/j.ibiod.2016.03.011

10. Saha A, Johnston TG, Shafranek RT, Goodman CJ, Zalatan JG, Storti DW, Ganter MA, Nelson A (2018) Additive Manufacturing of Catalytically Active Living Materials. ACS Appl Mater Interfaces 10(16):13373-13380. https://doi.org/10.1021/acsami.8b02719

11. Salmean C, Dimartino S (2019) 3D-Printed Stationary Phases with Ordered Morphology: State of the Art and Future Development in Liquid Chromatography. Chromatographia 82(1). https://doi.org/10.1007/s10337-018-3671-5

12. Schoen AH (2012) Reflections concerning triply-periodic minimal surfaces. Interface Focus 2(5):658-668. https://doi.org/10.1098/rsfs.2012.0023

13. Schure MR, Maier RS, Kroll DM, Davis HT (2004) Simulation of ordered packed beds in chromatography. J Chromatogr A 1031(1-2):79-86. https://doi.org/10.1016/j.chroma.2003.12.030

14. Shakeel Syed M, Rafeie M, Henderson R, Vandamme D, Asadnia M, Ebrahimi Warkiani M (2017) A 3D-printed mini-hydrocyclone for high throughput particle separation: Application to primary harvesting of microalgae. Lab Chip 17(14):2459-2469. https://doi.org/10.1039/c7lc00294g

15. Simon U, Scorza LCT, Teworte S, McCormick AJ, Dimartino S (2020) Demonstration of protein capture and separation using three-dimensional printed anion exchange monoliths fabricated in onestep. Journal of Separation Science, jssc.202000722. https://doi.org/10.1002/jssc.202000722

16. Smith PK, Krohn RI, Hermanson GT, Mallia AK, Gartner FH, Provenzano MD, Fujimoto EK, Goeke NM, Olson BJ, Klenk DC (1985) Measurement of protein using bicinchoninic acid. Anal Biochem 150(1):76-85. https://doi.org/10.1016/0003-2697(85)90442-7

17. Staby A, Sand MB, Hansen RG, Jacobsen JH, Andersen LA, Gerstenberg M, Bruus UK, Jensen IH (2005) Comparison of chromatographic ion-exchange resins: IV. Strong and weak cation-exchange resins and heparin resins. J Chromatogr A 1069(1):65-77.

https://doi.org/10.1016/j.chroma.2004.11.094

18. Tan R, Franzreb M (2020) Continuous ultrafiltration/diafiltration using a 3D-printed two membrane single pass module. Biotechnol Bioeng 117(3):654-661. https://doi.org/10.1002/bit.27233

19. Wang H, Cocovi-Solberg DJ, Hu B, Miró M (2017) 3D-Printed Microflow Injection Analysis Platform for Online Magnetic Nanoparticle Sorptive Extraction of Antimicrobials in Biological Specimens as a Front End to Liquid Chromatographic Assays. Anal Chem 89(22). https://doi.org/10.1021/acs.analchem.7b03767

20. Wang W, Ma T, Lian K, Zhang Y, Tian H, Ji K, Li G (2013) Genetic analysis of benzothiophene biodesulfurization pathway of Gordonia terrae strain C-6. PLoS ONE 8(12):e84386. https://doi.org/10.1371/journal.pone.0084386 


\section{Figures}

\section{Figure 1}

Schematic flow diagram for the design, manufacture and experimental testing of porous monoliths for applications in bioprocess engineering. (a) chemical structures of bifunctional monomers (CEA, AETAC, MAETAC, HEMA) employed, displaying (meth)acrylate groups for polymerization (blue) and active groups (red). (b) Simulated reduced plate height vs reduced velocity (Peclet) for the gyroidal scaffold (this work) and random packing of spherical particles (extracted from Schure et al., 2004). (c,f) CAD models of hollow cylinder and gyroid structures, respectively, together their 3D printed counterparts $(d, g)$. Experimental characterization of (e) hollow cylinders using 96 multi-well plate set-up in static (batch) mode and $(\mathrm{h})$ gyroid scaffold in column for dynamic testing.

\section{Figure 2}

Adsorption isotherms of (a) bovine serum albumin (BSA) on anion exchangers (based on AETAC monomer, adapted from Simon et al., 2020), and (b) lysozyme (LYS) on cation exchangers (based on CEA monomer). Ligand densities of 0 (control), $0.57,1.14,1.73,2.33 \mathrm{mmol} / \mathrm{mL}$ and of 0 (control), $0.77,1.56$, $2.36,3.23 \mathrm{mmol} / \mathrm{mL}$ were tested for the anion and cation exchanger, respectively. Isotherms were fitted with Langmuir model (continuous lines). Dashed lines corresponds to maximum binding capacity of equivalent commercial materials (Boi et al., 2020; Staby et al., 2005). (c) Separation of BSA $(16 \mathrm{mg} / \mathrm{mL}$ ) and myoglobin (MYO, $6 \mathrm{mg} / \mathrm{mL}$ ) on AETAC-based anion exchangers (1.6 mL column volume (CV), 1.73 $\mathrm{mmol} / \mathrm{mL}$ ligand density). $500 \mu \mathrm{L}$ injection in binding buffer $(20 \mathrm{mM}$ Tris, $\mathrm{pH} 8.0)$ followed by linear gradient from 0 to $30 \%$ elution buffer $(20 \mathrm{mM}$ Tris, $1 \mathrm{M} \mathrm{NaCl}, \mathrm{pH} 8.0$ ) over $20 \mathrm{CV}$ at $1.0 \mathrm{~mL} / \mathrm{min}$. First peak is flow-through of overloaded BSA and MYO, second and third peaks correspond to MYO elution at $7.4 \mathrm{CV}(3.1 \mathrm{mS} / \mathrm{cm})$ and BSA elution at $18.7 \mathrm{CV}(19.0 \mathrm{mS} / \mathrm{cm})$ in line with the electrostatic interactions established at the buffer's $\mathrm{pH}$ of $8\left(\mathrm{pl}_{\mathrm{BSA}}=4.8 ; \mathrm{pl}_{\mathrm{MYO}}=7.0\right)$. (d) Separation of BSA $(16 \mathrm{mg} / \mathrm{ml})$ and LYS (4 $\mathrm{mg} / \mathrm{ml}$ ) on CEA-based cation exchangers $(2.5 \mathrm{~mL} \mathrm{CV}, 3.23 \mathrm{mmol} / \mathrm{mL}$ ligand density). $300 \mu \mathrm{L}$ injection in binding buffer ( $25 \mathrm{mM}$ phosphate, $\mathrm{pH} 7.4$ ) followed by linear gradient from 0 to $100 \%$ elution buffer (25 $\mathrm{mM}$ phosphate, $1 \mathrm{M} \mathrm{NaCl}, \mathrm{pH} 7.4$ ) over $20 \mathrm{CV}$ at $1.0 \mathrm{~mL} / \mathrm{min}$. First peak is flow-through of non-binding BSA $\left(\mathrm{pl}_{\mathrm{BSA}}=4.8\right)$ and overloaded LYS, second peak corresponds to LYS elution at $7.6 \mathrm{CV}(33.4 \mathrm{mS} / \mathrm{cm})$ in line with the electrostatic interactions established at the buffer's $\mathrm{pH}$ of $7.4\left(\mathrm{pl}_{\mathrm{LYS}}=11.4\right)$. 
(a)

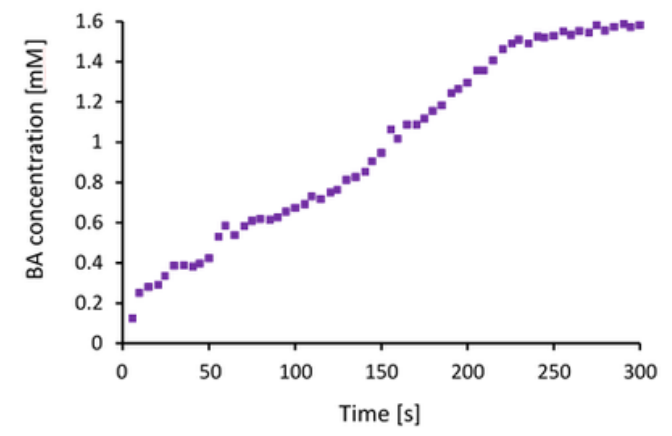

(b)

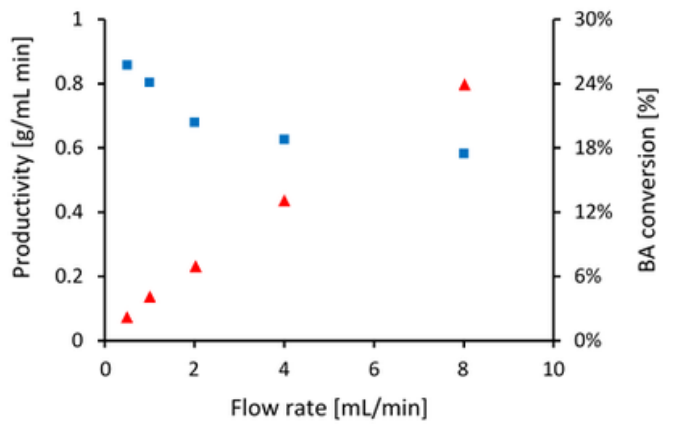

\section{Figure 3}

(a) Formation of the BA hydrolysis product over time using a 3D printed monolith with $7.31 \mathrm{mg} / \mathrm{g}$ immobilised trypsin. (b) BA conversion (blue) and productivity (red) obtained from continuous operation of immobilized enzyme bioreactor with Schoen gyroid bed geometry in steady state mode at different flow rates. 
(a)

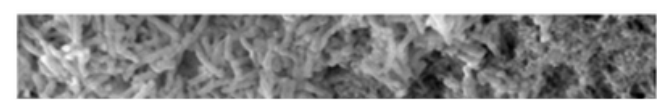

(b)

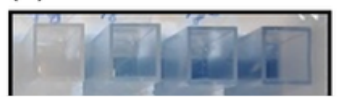

\section{Figure 4}

(a) SEM of MAETAC monomers revealing bacterial biofilm adhered onto 3D printed support after 3 days incubation with $R$. opacus culture in exponential growth phase. $\mathrm{BT}$ is desulfurized by $R$. opacus into phenolic end products, as detected using Gibbs test on perfusate samples visualized by blue colour (b) and measured at $610 \mathrm{~nm}$ (c).

\section{Supplementary Files}

This is a list of supplementary files associated with this preprint. Click to download.

- FlexibleApplicationsPaperSISD.docx 